\title{
Effect of ingestion of paraquat on a 20-week gestation fetus
}

\author{
F. A. MUSSON \\ M.R.C.O.G.
}

\author{
C. A. PORTER \\ M.R.C.P.
}

Royal Victoria Hospital, Folkestone, Kent

\begin{abstract}
Summary
A woman ingested a small amount of paraquat when 20 weeks pregnant. There appeared to be no effects on the fetus.

\section{Introduction}

There is no published information to our knowledge of the effect of paraquat on a 20 -week-old fetus. The following case provides some.
\end{abstract}

\section{Case report}

The patient, who was 20 weeks pregnant, drank a few sips of 'Weedol' containing paraquat in a suicide attempt. One hour afterwards she was given a stomach washout and 30\% Fuller's Earth orally, 2 hourly, for 24 hours and then 4 hourly for $24 \mathrm{hr}$. She also had $40 \mathrm{mg}$ frusemide intramuscularly with the first dose. Her blood paraquat levels estimated by radioimmunoassay technique were: $1 \mathrm{hr}$ after drinking paraquat: $18 \mu \mathrm{g} /$ litre; $3 \mathrm{hr}$ after drinking paraquat: $8 \mu \mathrm{g} /$ litre; $8 \mathrm{hr}$ after drinking paraquat: less than $1 \mu \mathrm{g} /$ litre. These blood levels are about $0.1 \%$ of those endangering an adult (Vale \& Meredith, 1981), but a search of the literature yielded no indication of what effect might be found on the human fetus.

The pregnancy was allowed to continue and the patient went into labour spontaneously at term. The baby weighed $3.36 \mathrm{~kg}$, which was almost as much as her three previous babies (3.66-3.94 kg). The Apgar score was 8 at birth and 9 at $5 \mathrm{~min}$. The placenta weighed $700 \mathrm{~g}$ and was infarcted and gritty, although the patient had no history of toxaemia and did not smoke.

She discharged herself with her infant but the infant was re-admitted at 9 days with jaundice and $284 \mathrm{~g}$ weight loss. The serum bilirubin at 10 days was $195 \mu \mathrm{g} /$ litre. The total bilirubin rose to a maximum of $280 \mu \mathrm{g} /$ litre, all of which was unconjugated. There was no bilirubin in the urine. She again discharged herself against advice. The infant was followed up to

Requests for reprints to: Dr F. A. Musson, 32 High Street, Charing, Kent. the age of 3 years and did well clinically, being normal on developmental and neurological examination. Screening liver function tests at 3 years were normal except for a transiently raised alkaline phosphatase (587 iu./litre) at 3 years. Isoenzyme studies gave presumptive evidence that this was of bone origin.

Our conclusion so far is that this small dose of paraquat, promptly treated, did not adversely affect the 20 week fetus.

\section{Discussion}

Animal studies for teratogenicity on the rat showed only skeletal abnormalities at the costochondral junctions and traces in the fetal lungs when isotopemarked paraquat was given to rats in the first month of gestation (Khera, Shitta and Clegg, 1970). Traces of paraquat were also shown to pass transplacentally in the mouse when large doses were given. Although it led to an increased fetal death rate, no specific fetal abnormality was found (Haley, 1979).

We could find no work on transplacental transfer of paraquat in higher vertebrates. The only indication as to whether a human fetus might be affected was an account of a woman of 28 weeks gestation who died of paraquat poisoning 20 days after ingestion (Fennelly, Gallagher and Carroll, 1968). At post mortem the fetus showed no tissue changes.

The outcome for the human fetus in the present case is recorded to aid any gynaecologist presented with the question of termination for a teratogenic risk from paraquat.

\section{Acknowledgment}

We would like to thank the Guy's Hospital Poisons Unit (New Cross Hospital) for performing the paraquat assay.

\section{References}

Fennelly, J.J., Gallagher, J.T. \& Carroll, R.J. (1968) Paraquat poisoning in a pregnant woman. British Medical Journal, 3, 722.

HALEY, T.J. (1979) Review of toxicology of paraquat. Clinical Toxicology, 14, 19. 
Khera, K.S., ShitTA, L.L. \& ClegG, D.J. (1970) Embryopathic effect of diquat and paraquat. In: Pesticides Symposia Interamerican Congress on Toxicology and Occupational Medicine, (Ed by Deichmann, W.B., Radomski, J.L. \& Penalver, R.A.), pp. 257-261. Halos and Ass. Inc., Miami.
VAle, J.A. \& Meredith, T.J. (1981) Poisoning Diagnosis and Treatment, p. 135. Update Books, London. 